\title{
Acerca do jogo
}

"A propos du jeu", Actes Sémiotiques-Documents, n. 13, 1980, p. 29-34. Ao que parece, o texto que ora apresentamos em traduçăo anotada (cf. o pós-escrito do tradutor ao final do artigo) teve até o momento apenas duas traduçōes: uma italiana ("A proposito del gioco". In: GREIMAS, A. J. Miti e Figure. Trad. de F. Marsciani. Bologna: Esculapio, 1995) e uma brasileira ("A propósito do jogo". Verso \& Reverso, n. 27. Trad. de Elizabeth Bastos Duarte. São Leopoldo: Unisinos, 1998). Agradeço a Ana Carolina Cortez Noronha, Arnaldo Cortina, Ivã Carlos Lopes e Matheus Nogueira Schwartzmann pela leitura atenta que fizeram da primeira versão deste texto. Agradeço igualmente a Teresa Keane-Greimas que, além de aprovar a tradução em língua portuguesa do artigo, fez-me também valiosas sugestões.

[N. do T.] 
Prof.Dr. Eduardo Peñucla Cañizal,

Significaçao - Revista Brasileira de Semiótica,

Rua Capitâo Nicolau Puccini, 118 ,

Jardim Bonafiglioli,

Sâo Paulo.

Monsieur,

$\mathrm{j}^{\star}$ autorise, par la présente, la publication dans votre revue, Significacâo, de la traduction en languc portugaise de l'article de A.J. Greimas « ̇̀ propos du jeu ». La traduction, téalisće par Jcan Christtus Portela, est intituléé "Acerca do jogo ».

Je profite de l'occasion pour vous remercier de l'intérêt que vous continuez de porter à l'œuvre de Greimas qui remonte à l'entretien de 1973 sur l'énonciation. C'était, en fait, un article de fond de grande importance, qui a circulé partout dans le monde grâce à votre revue.

On peut espérer que la publication de l'article ci-dessus marquera un nouveau départ dans la traduction de son cuvre en langue portugaise et je salue, au passage, l'enthousiasme ainsi que la compétcnce du traducteur avec qui j'ai pu m'cntretenir lors de sa venue à Limoges.

S'il était là, Greimas dirait sûrement, et je me permets donc de le dire à sa place, " lc peuple reconnaissant »!

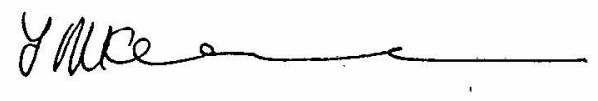

Fait à Paris le 27 mars 2007

Teresa Keane Greimas

. 


\section{Resumo}

Este trabalho propõe uma breve análise do uso da analogia do jogo de xadrez nas ciências da linguagem (F. de Saussure, L. Hjelmslev, L Wittengstein). Após algumas considerações sobre a natureza do jogo e sua compreensão como situação de interação entre dois sujeitos, passa-se, por meio da análise semântica do lexema "jogo", à análise do percurso do sujeito "jogador" e de suas estratégias.

\section{Palavras-chave}

Jogo de xadrez, sistema, interação, estratégia, Semiótica.

\section{Abstract}

This work proposes a brief analysis on the use of the chess game analogy in the language sciences (F. de Saussure, L. Hjelmslev, L.Wittengstein). After some considerations on the nature of chess game and its understanding as a situation of interaction between two subjects, this paper presents, by the semantic approach of the lexeme "game", the analysis of the narrative process of the subject "player" and its strategies.

\section{Key words}

Chess game, system, interaction, strategy, Semiotics. 


\section{Jogo e linguagem}

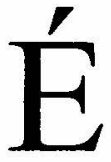

no mínimo curioso constatar que a maior parte dos "pensadores" do século 20 que refletiram sobre os problemas da linguagem - Husserl, Saussure, Wittgenstein, Hjelmslev - em algum momento, tomaram o jogo - e mais particularmente o jogo de xadrez - como modelo para sua reflexão. Esse emprego metafórico do jogo, que o transforma em uma linguagem figurativa que permite falar da linguagem, não foi previamente convencionado e tampouco pode ser considerado como efeito do acaso. Ele se inscreve, provavelmente, na episteme profunda do século.

Refletir sobre o jogo é, para nós, refletir sobre a linguagem e, de uma forma mais abrangente, sobre nossa maneira de ser no mundo significante.

\section{Coerção e liberdade}

O jogo apresenta-se ao mesmo tempo como um sistema de coerções, formuláveis por meio de regras, e como um exercício de liberdade, como uma distração. Mas essa liberdade é, à primeira vista, somente um ato isolado que se limita à entrada no jogo por meio da assunção voluntária das regras coercitivas. A entrada no jogo é livre, mas não a saída: o jogador não pode nem abandonar o jogo - ele "amarelaria"- nem deixar de obedecer às regras - ele trapacearia. $\mathrm{O}$ código do fair play é tão rigoroso quanto o código de honra.

Uma primeira incongruência: enquanto penetramos livremente em um sistema lúdico, somos previamente condenados a 
viver no interior dos sistemas "sérios", sob o risco de buscarmos desesperadamente transgredi-los por um ato liberatório.

\section{O jogo como sistema}

Modelo figurativo que ajuda a pensar a linguagem, o jogo de xadrez é suscetível, conseqüentemente, de uma leitura pluri-isotópica.

Ele é, antes de mais nada, um modelo que permite compreender a natureza de um "sistema de signos". Cada figura se define não pelo que é, mas por seu comportamento, que a distingue das outras. O signo torna-se, assim, uma simples posição, o ponto de intersecção dos percursos. A dessubstancialização dos signos permite, então, pensar o sistema como uma forma. Por outro lado, como cada uma das figuras depende de todas as outras, cada um de seus movimentos abala o sistema, criando um novo estado estrutural, fundado sobre um novo equilibrio provisório. O conceito de sistema formal leva, assim, a pensar a história como uma descontinuidade feita de estados e transformações.

É tentador, a partir dessas considerações, identificarmos essas posições vazias, figuras para indivíduos que atuam no interior de sistemas que os superam e manipulam. Suas possibilidades de ação, compreendidas como percursos autorizados, encontram-se a todo instante limitadas e contraditas pelo comportamento de seus vizinhos, bem ou mal intencionados. A imagem de uma sociedade feita de figuras desencarnadas e despersonalizadas serviu, há não muito tempo, para celebrar, por um momento, a glória masoquista e para proclamar, em seguida, a degradação libertadora do "estruturalismo" filosófico.

\section{O jogo dos atores}

A problemática muda inteiramente de figura se, ao invés de considerarmos unicamente o tabuleiro de xadrez, levantarmos o olhar para perceber a presença dos jogadores e para tentar compreender o que acontece, em termos de condições prévias (ou de pressuposições 
lógicas que condicionam seus gestos lúdicos), em suas cabeças. Dessa forma, nos damos conta de que os deslocamentos espaciais das figuras sobre o tabuleiro são apenas manifestações litóticas dos programas de jogo complexos que subsumem os encadeamentos de ações já concluídas e os projetos de ações ainda por vir. Em outras palavras, as unidades lúdicas que devem ser levadas em consideração, não sã̃o mais atos de jogo particulares, mas ações discursivas programadas. Não se trata, no jogo, da aplicação mais ou menos satisfatória de uma regulamentação, mas de um face a face de dois sujeitos cognitivos dotados de um conhecimento implícito das regras, que eles exploram para elaborar, sob a forma de programas virtuais complexos, estratégias que devem conduzi-los à vitória.

A estratégia de que se trata aqui não provém somente daquilo que podemos chamar uma inteligência sintagmática ou, ainda, de uma faculdade de construir encadeamentos de atos-enunciados eficazes. Ela implica, antes de mais nada, uma competência interpretativa das perfórmances do interlocutor, permitindo ao sujeito remontar dos atos às intenções do adversário e também constituir para si uma representação global de seu saber, de seu querer e de seu poderfazer. Ela é, por outro lado, uma competência manipuladora. Os programas construídos pelo sujeito não são todos destinados a conduzir o jogo a seu termo, eles consistem, muitas vezes, em fazer-crer que visamos este ou aquele objetivo e em fazer-fazer, em fazer agir o interlocutor no contexto e em proveito do programa mais amplo de seu adversário. $O$ jogo de xadrez é, então, somente um pretexto, ele constitui o nível referencial a partir do qual se desenvolve uma atividade cognitiva de segundo grau, um jogo de dissimulações e estratagemas.

Desse modo, não é legítimo considerar os jogadores implicados em uma partida no hic et nunc como actantes abstratos. Eles são sujeitos "históricos", e isso de um duplo ponto de vista, na medida em que, além de possuírem uma competência semântica específica que se deve em grande parte a suas perfórmances anteriores, possuem também uma competência modal mais ampla que, indiferente ao campo de exercício do jogo escolhido, determina seu fazer programador, tanto interpretativo como persuasivo. 
Além do sistema lúdico propriamente dito, uma organização cognitiva pode ser reconhecida e construída a partir de uma tipologia das competências e de suas interações.

\section{Xadrez e computadores}

É tentador - e já se tentou - colocar o computador no lugar de um dos jogadores, dotando-o de uma inteligência artificial capaz de decifrar um grande número de combinações de atos de jogo estereotipados e de lhes dar respostas apropriadas. Todavia, um autômato dessa natureza somente tem condições, ao que parece, de enfrentar jogadores suficientemente medíocres ${ }^{1}$. A máquina operando, em um primeiro tempo, no nível "referencial" do jogo não seria capaz de interpretar os programas lúdicos que não fossem fundados na busca da vitória, mas regidos pelo sistema modal de segundo grau que produz configurações de jogo que não significam aquilo que parecem querer significar. Essa estratégia de estratagemas e contraestratagemas pode, teoricamente, ser sistematizada e introduzida no computador sob a forma de uma nova gramática de reconhecimento. Mas, como naquele jogo infantil no qual se deve adivinhar se a pedra está na mão esquerda ou na mão direita, o sistema de previsibilidade há pouco estabelecido pode ser superado novamente pelo jogador humano. O jogo continua... E alimenta a ilusão de um pouco de liberdade ${ }^{2}$.

1. Os tempos são outros, tanto do ponto de vista da máquina (hardware) quanto das linguagens de programação (software), como mostrou, em 1997, a vitória do computador Deep Blue, da IBM, sobre o russo Gary Kasparov, então campeão mundial de xadrez. [N. do T.]

2. Embora a análise de Greimas seja sedutora pelo que tem de poético, até mesmo à luz da Ciência da Computação da época, ela não se revela pertinente. Ora, em princípio, o objetivo "declarado" do jogo, a despeito de todo estratagema ou contra-estratagema de manipulação é, por fim, a vitória. No xadrez, o que está em jogo na competência do sujeito cognitivo (seja ele manifestado por homem ou por "máquina", o que equivale a dizer, "por outros homens que programam uma máquina") não é a complexidade do sistema modal, que se encontra altamente limitado pela busca da vitória, mas, sim, a quantidade de operações (de jogadas, de conjuntos de jogadas, enfim, de estratégias) que o sujeito cognitivo é capaz de simular e antecipar. Na verdade, a visão greimasiana revela sua acuidade na 


\section{Jogo e comunicação}

$O$ lingüista, acostumado a refletir no âmbito de seus próprios conceitos, não pode deixar de evocar, quando ele se encontra, como é o caso, na presença de dois sujeitos que interagem entre si, o modelo familiar da estrutura da comunicação. Ele não pode deixar de ver no jogo uma forma de comunicação, ainda que isso signifique procurar determinar, em seguida, sua especificidade.

O diálogo intersubjetivo, por menos que ultrapasse a função fática que lhe é normalmente atribuída, comporta uma finalidade veridictória. Dizer algo não é deliberar sobre uma conjuntura, é, antes de tudo, procurar convencer, de um jeito ou de outro, seu interlocutor. As coisas não se passam de outra forma quando se trata do jogo. Em todo jogo há sempre algo em jogo: cada um dos jogadores se dedica a elaborar um programa discursivo global que visa à vitória final. Se o jogo contém, como nos dizem os dicionários, uma parte de prazer, esta não provém unicamente da exaltação solitária de seu próprio poderfazer, ela decorre, ao mesmo tempo e sobretudo, de um fazer-saber. A vitória só é completa se, oferecida a seu interlocutor, ela for sancionada pelo reconhecimento do outro. No jogo, não se trata somente de vencer, mas de con-vencer, de obrigar a partilhar de seu triunfo.

O raciocínio analógico que se serve do modelo lúdico permitenos insistir em um aspecto muitas vezes pouco conhecido da comunicação. Tanto quanto ou mais do que a exploração de um "código comum" ou do que uma "generosidade" que regeria, segundo alguns filósofos, as relações intersubjetivas, a comunicação é um confronto de quereres e poderes. Mais do que a enunciação de verdades e de falsidades, ela se submete ao princípio da eficácia.

A eficácia das programações do jogador repousa decididamente, assim como as operações propriamente lúdicas que ele constrói, sobre as manipulações do saber de seu interlocutor. As

distinção que sugere entre inteligência humana e artificial, que repousaria no fato de a inteligência humana ser sobredeterminada por um sistema modal subjetivo, instável pois desejante, por vezes contraditório, que pode instalar o caos, mesmo em meio à ordem do jogo. Ao passo que a máquina, cartesiana, limitada pela não-contradição, só conheceria o rigor do /dever/.[N. do T.]

Significação $27 \cdot 18$ 
configurações manipulatórias que ele oferece a sua interpretação são concebidas de forma a serem incompreendidas ou mal compreendidas por seu interlocutor. No limite, o jogador somente pode estar seguro de que ganhará, caso personalize o jogo até que ele se torne incomunicável. Essas seqüências ilusórias, por outro lado, na medida em que não falam sobre aquilo que são aparentemente destinadas a falar, já constituem o esboço de uma linguagem figurativa segunda - admitindo que as línguas naturais só são chamadas de linguagens justamente porque não falam de sons.

A eficácia, ligada à incomunicabilidade e à figuratividade: eis os traços comuns que o jogo de xadrez - mas também outros jogos - partilham com a linguagem poética.

\section{Jogo e desenvoltura}

Todo o sistema normativo feito de injunções, isto é, de proibições e prescrições, comporta as posições vazias do não-proibido e do não-prescrito, suscetíveis de serem exploradas por sujeitos do fazer. É nesse sentido que podemos dizer que uma estrutura tem "um jogo", que ela tem algo de jogo ${ }^{3}$. Com exceção, talvez, dos sistemas políticos (entre outros), que praticam o binarismo estrito, nos quais tudo que não é prescrito é proibido, e inversamente. A ausência do jogo equivale, assim, à ausência da liberdade.

Façamos um pequeno exercício de semântica aplicada. Segundo os dicionários, o jogo implica a "desenvoltura" e se define, em uma de suas acepções, como o "movimento desenvolto de um objeto no espaço". A desenvoltura, por sua vez, é a "maneira de ser

3. No original, apenas "la structure a 'du jeu". A paráfrase empregada na tradução procurou desenvolver os dois sentidos que a construção partitiva "du jeu" pode manifestar em francês: a qualidade do que é lúdico, próprio ao jogo, e a do que está frouxo, mal ajustado. Em português, essas nuanças sảo claras em enunciados do tipo: "há neste romance algo de jogo" e "esta roda tem um pequeno jogo". [N. do T.]

4. Segundo o Houaiss, o jogo pode ser o "movimento natural, regular, de um objeto, de um orgão, de um mecanismo". O Michaelis não é mais preciso a respeito: "espaço livre entre duas peças, tais como eixo e mancal, ou êmbolo e cilindro; folga, interstício, luz".[N. do T.] 
livre daquele que se sente à vontade". Apesar da aparente circularidade dessas definições, nelas podemos destacar, além da parassinonimia dos termos "jogo", "desenvoltura", "liberdade", o caráter discursivo acentuado da última explicitação. Tentemos decompô-la como segue:

1. O enunciado de base define o sujeito lúdico como estando "à vontade". Digamos que se trate, nesse caso, de um sujeito do fazer exercendo sua atividade no contexto permissivo do não-proibido e do não-prescrito. Se chamarmos de Fl o conjunto dos fazeres que o sujeito é suscetivel de executar obedecendo às injunções, podemos designar como F2 os fazeres que ele pode realizar conformando-se às posições "livres" do sistema de coerções. O estado "à vontade" do sujeito pressupõe, então, a passagem de F1 a F2.

2. É quando se encontra no estado operativo $F 2$ que o jogador torna-se "aquele que se sente à vontade". A atividade que ele exerce nesse estado provoca no sujeito um efeito de sentido particular que constitui o estado passional P1, considerado como "o sentimento de estar à vontade".

3. Esse efeito de sentido é um estado que (como o estado de "crer", por exemplo) é capaz de agir em resposta a seu comportamento, otimizando-o e produzindo essa "maneira de ser livre" que define a desenvoltura no jogo. Pela mediação do estado passional P1, F2 engendra um F3 multiplicado à máxima potência.

4. Assim, não é nada surpreendente que esse fazer otimizado produza um novo efeito de sentido e um novo estado passional P2, na medida em que os mesmos dicionários definem a desenvoltura como a "plenitude da felicidade".

É por meio de uma sintagmática bem complexa:

$$
\mathrm{F} 1 \rightarrow \mathrm{F} 2 \rightarrow \mathrm{P} 1 \rightarrow \mathrm{F} 3 \rightarrow \text { P } 2
$$


que o homem, preso inicialmente em sistemas de coerções, consegue não somente "sentir-se à vontade", mas também assumir essa "maneira de ser livre" que garante a sua "plenitude". Talvez a linguagem não seja completamente uma prisão sem saídas, como querem alguns.

A. J. Greimas

1979

\section{Pós-escrito do tradutor}

Este é um dos poucos textos que A. J. Greimas decidiu não incluir posteriormente em seus "ensaios semióticos" - ao contrário, por exemplo, de "Description et Narrativité", texto que precede " $A$ propos $d u$ jeu" no mesmo número dos Documents (n. 13, 1980), e que aparecerá três anos mais tarde em Du Sens II. O leitor não deixará de notar o quanto este artigo tornou-se datado no que diz respeito ao progresso das Ciências da Computação no âmbito da Inteligência Artificial aplicada ao jogo de xadrez. No entanto, no que toca às considerações propriamente semióticas sobre o jogo e suas coerções, este pequeno texto mantém seu interesse e pertinência. Acreditamos que a maior prova da atualidade deste estudo é, sem dúvida, a abordagem do jogo como uma autêntica "forma de vida", expressão tomada a Wittgenstein que não aparece aqui e que será explorada por Greimas em seus últimos escritos.

Supondo que o lexema "cientifico" signifique realmente algo em Ciências Humanas e Sociais ("objetividade"? "neutralidade"? termos monossêmicos e interfinidos?), pode-se dizer que, se, por um lado, o texto greimasiano guarda fortes características "científicas" quanto à análise e à formalização de seus objetos de estudo, por outro, é preciso reconhecer que, na obra greimasiana, embora em pequeno número (se pensarmos em Barthes e em Lacan, conhecidos maneiristas), a ironia da alfinetada elegante, a poesia viva do comentário discretamente epífano, e mesmo a "private joke, não são raras.

Em "Acerca do jogo", por exemplo, ao lado de uma das metalinguagens mais cerradas do cenário das Ciências da Linguagem, coexistem a língua informal, presente no uso de "amarelar" ("se dégonfler"), a analogia acessivel do "jogo infantil" e considerações como: "o código do fair play é tão rigoroso quanto o código de honra" ou, ainda, a lapidar 
"talvez a linguagem não seja completamente uma prisão sem saídas, como querem alguns", com a qual Greimas encerra sua reflexão.

A presente tradução pretendeu transpor, sempre que possível, o texto greimasiano para a sensibilidade do leitor brasileiro (promessa e logro de toda a tradução). A respeito da famigerada e sobrenatural discrição e transparência do verdadeiro e bom tradutor, só me resta repetir - sem nenhuma originalidade e arriscando incorrer, para alguns, na mais pura vulgaridade - as palavras sábias e célebres de uma implacável e pouco original professora que tive no primário: "carne de burro não é transparente!".

Que não se enganem os leitores: embora "franco" (eis uma estratégia manipulatória que tem seu charme, ainda que esteja, é verdade, um pouco desprestigiada), este tradutor é demasiadamente humano, cego que é, como quase todo "bom mau" tradutor de semiótica, a certos galicismos imperdoáveis. Procurei fazer o possível para que uma leitura equivocada minha (má leitura, má tradução... ou o contrário?), combinada à dificuldade natural da metalinguagem, não prejudicasse a compreensão do texto.

Dizia um sujeito, dos desconfiados: "Para se ler uma tradução de um texto de Semiótica, é preciso, no mínimo, já saber Semiótica!'. De minha parte, pergunto-me simplesmente: quando daremos à tradução teórica o mesmo estatuto de transcriação que já há muito alcançou a tradução poética? Muito provavelmente, teremos, antes, que admitir que fazer Ciência é a mais arriscada das Artes.

Jean Cristtus Portela Limoges, agosto de 2006 